Association for Information Systems

AIS Electronic Library (AISeL)

Wirtschaftsinformatik 2021 Proceedings

Track 17: Digital transformation \& business

models

\title{
What is Meant by Digital Transformation Success? Investigating the Notion in IS Literature
}

Philipp Barthel

Ludwig-Maximilians-Universität München

Follow this and additional works at: https://aisel.aisnet.org/wi2021

Barthel, Philipp, "What is Meant by Digital Transformation Success? Investigating the Notion in IS Literature" (2021). Wirtschaftsinformatik 2021 Proceedings. 1.

https://aisel.aisnet.org/wi2021/HDigitaltransformation17/Track17/1

This material is brought to you by the Wirtschaftsinformatik at AIS Electronic Library (AISeL). It has been accepted for inclusion in Wirtschaftsinformatik 2021 Proceedings by an authorized administrator of AIS Electronic Library (AISeL). For more information, please contact elibrary@aisnet.org. 


\title{
What is Meant by Digital Transformation Success? Investigating the Notion in IS Literature
}

\author{
Philipp Barthel \\ LMU Munich, Institute for Information Systems and New Media, Munich, Germany \\ barthel@bwl. lmu. de
}

\begin{abstract}
Companies across all industries currently strive to successfully master their digital transformation. While information systems research to date has strongly emphasized identification of how companies achieve digital transformation success, the literature is still strikingly vague regarding the notion of digital transformation success itself and approaches to measure it. Therefore, we have conducted a systematic literature review to investigate how information systems studies discuss the concept of digital transformation success and which approaches to success measurement they propose and apply. Based on our analysis, we identify four clusters that represent different understandings of digital transformation success and 20 success dimensions that concretize success measurement. This study clarifies the notions of digital transformation success currently in use and outlines new avenues for information systems research. Further, the results inform practitioners regarding different options and approaches to assess digital transformation success.
\end{abstract}

Keywords: Digital Transformation, Success, Literature Review.

\section{Introduction}

In recent years, digital transformation (DT) has emerged as one of the central topics in both research and practice [1]. In the course of the DT process, organizations can fundamentally redefine their established value propositions and value creation logics [2]. Consequently, organizations across nearly all industries have to rethink their processes, products, services, and business models [3]. To accomplish this task, changes to different organizational properties are often necessary [1], [4], [5]. Unsurprisingly, there is a rich body of literature on factors that have to be fulfilled in order to reach successful DT in an organization [6-8]. However, extant literature is often vague in referring to the concept of DT success itself. This could be because DT is an on-going, open-ended process, with high complexity, multidimensionality, and an extensive scope [5], [6]. Nevertheless, while "if you can't measure it, you can't manage it" might be an overstretched adage, prior research stresses how important identifying and evaluating the value contribution of DT efforts is in order to prioritize relevant issues and steer the DT process [9], [10].

Determining and clarifying information systems (IS) success has a longstanding research history (e.g., [11], [12]). More recently, research has addressed the matter of 
DT success from different perspectives and with different foci. Several studies have identified and analyzed DT success factors (e.g., [7], [8], [13]). This literature primarily addresses the factors that bring about DT success, not necessarily the factors that are part of success itself. Another type of study discusses potential DT outcomes, such as financial improvement or increased market share (e.g., [14], [15]), but either focuses on a specific area of DT, or only marginally addresses DT outcomes. In all, the underlying understanding of DT success is rarely touched on in extant research. There are a few exceptions, which discuss DT success more thoroughly and in-depth (e.g., [6], [10], [16]). However, none of these papers claims to cover the current discourse in its entirety, and each investigates a different paradigm of DT success. Due to the topic's complexity, we require a comprehensive and systematic overview of what is meant by the term DT success. Therefore, we aim to capture the different notions of DT success in the present academic debate, including approaches to measure such success. IS research and practice can strongly benefit from a clearer and more comprehensively structured picture of how DT success is conceptualized, discussed, and measured. The research question we address is: How is DT success conceptualized in IS literature?

To answer this research question, we conducted a systematic literature review. We have derived different success dimensions from the identified literature and clustered them according to the underlying notions of DT success. Based on this analysis, we formulated an agenda for further research that can serve as a starting point for future research in this field. This study contributes to the literature by providing a structured and systematic overview of the different notions of DT success and gives insight on related approaches to success measurement. Especially, we want to create a basis for discussing DT success, adding to precision and transparency in the debate. Also, we lay a foundation for researchers that aim to investigate DT success evaluation as applied in practice, or that operationalize DT success measurement themselves. Additionally, this study can support practitioners in clarifying their expectations regarding the benefits DT holds for organizations and in selecting suitable measurement approaches.

\section{Underlying Research Foundations}

In the following section, we give a brief overview of the research on IS success and then elaborate on the underlying concept of DT, which guides our literature analysis.

IS Success. Research on IS success is an established and comprehensive strand within IS research, covering a range of different concepts, such as IS (business) value (e.g., [12], [17]) and IS impact (e.g., [18]). Demonstrating the value of information technology (IT) is an essential component of IS research that confirms its legitimacy [12], [17]. However, this research strand is not based on a uniform understanding of the various concepts, and there is no broad clarity on what IS success is and how it should be measured [12], [16]. Disagreement mainly arises regarding the assessment of "hard" vs. "soft" criteria and "macro" vs. "micro" level measurements [19]. There is, however, general consensus that IS success is a multidimensional and interdependent phenomenon that becomes manifest on different levels (e.g., market, firm, individual) [11], [18]. Many scholars find capturing IT's latent and intangible value and causally 
linking it to a given outcome such as firm performance [12], [17], as main challenges. This becomes even more difficult when value is created not only within an organization, but also across company boundaries, on an interorganizational level [20], [21]. The complexity related to determining IS' overall success sometimes results in the arbitrary selection of single items, neglecting the multidimensionality and interdependence of success categories [11]. These issues have often led to IS evaluation being inefficient, ineffective, or entirely ignored [19]. Thus, decisions on investment in IS are often based on opaque and incomprehensible grounds, which result in poor selection and management of investments [22]. Overall, research on IS success seeks to resolve these issues, improving measurement of IS success for both academic and practical purposes, thus enabling better understanding and decision making.

IS success research offers an important theoretical foundation for analyzing different notions of DT success. While IS success primarily deals with IT applications' and systems' value, often focused on process improvement [12], [20], DT success goes beyond implementing technology, involving elements of business innovation and transformation. Therefore, the latter requires dedicated consideration.

Digital Transformation. DT can be defined as "a process that aims to improve an entity by triggering significant changes to its properties through combinations of information, computing, communication, and connectivity technologies" [5, p. 118]. This process goes beyond the digitization of resources and can involve the transformation of processes, products, services, and business models [3]. There is an ongoing discussion on whether and how DT and digital innovation are connected. The line of argumentation we follow in this paper is that DT should be considered as an innovation process based on digital innovations [4], [7], [23]. These digital innovations are achieved by combining an innovative digital business concept and an innovative digital (technological) solution [3]. Digital innovations can drastically change an organization's value proposition and thus its entire identity [24]. In this regard, DT differs from other forms of IT-enabled organizational transformation that rather reinforce an organization's established value propositions and identity [2].

The potential outcomes and benefits of digital innovation processes, and therefore also DT can be manifold and become manifest on various organizational levels [24], [25]. Accordingly, organizations can pursue different objectives with altered foci regarding their DT activities [26], [27]. However, measuring and evaluating whether these objectives have been achieved turns out to be challenging, e.g., due to the transformation activities' objectives being vaguely stated, unpredictable, or open-ended [4], [28]. This can lead to situations in which organizations have no clear overview of their DT activities' value contribution and thus are struggling to prioritize high value activities and terminate low value activities [29]. While companies can apply practices like digital value assurance to improve oversight [9], there is still high demand for approaches that will clarify and measure the success of DT activities [10]. Otherwise, the risk is that DT activities will experience a legitimacy crisis [23], [30]. To lay a basis for these advancements, we believe a systematic literature review targeting current notions of DT success will provide a valuable starting point. 


\section{$3 \quad$ Research Method}

To answer the research question, we conducted a systematic literature review. Literature reviews aim to critically examine and synthesize the current state of knowledge on a specific topic, to identify potential knowledge gaps and biases in the literature and to provide a basis for future research [31]. To ensure systematicity and transparency of the literature review, we followed the guidelines Paré et al. [32] proposed. These include documenting the research process in a comprehensive review protocol. To build the literature sample, we followed a two-phased search process [33]. In the first phase, we conducted a keyword search in the titles, abstracts, and keywords of the eight journals comprising the AIS Senior Scholars' Basket. In doing so, we aimed to capture high quality research in the IS field. In order to also find contemporary research, we included the proceedings of the major IS conferences ICIS, ECIS, WI, PACIS, HICSS, and AMCIS. The search terms consisted of combinations of two elements. First, to find papers addressing digital transformation success, the search terms "digital transformation" / "digital innovation" / "digitali(s|z)ation" were selected. As argued, we included digital innovation because it is considered to be a core element of DT (e.g., [3], [4], [23]). Further, we included the term digitalization because it is regularly applied to describe processes that fit the definition of DT applied here (e.g., [10], [34], [35]). We excluded any papers in which the phenomenon addressed did not fit the applied DT definition [5]. Second, to find papers addressing digital transformation success, we applied the terms "success" / "impact" / "performance" / "outcome" / "result" / "benefit" / "value". These keywords were selected in accordance with practices followed in prior research [10], [16]. The keyword search yielded 399 results, which we screened to remove all papers that discussed DT success only marginally, as well as all editor's comments, book reviews and research-in-progress papers. Finally, 76 papers remained to be considered for further analysis.

In the second phase, we conducted a forward and backward search following Webster and Watson [33]. With this search, we extended the sample by 45 papers from IS outlets. The resulting 121 papers were then further assessed regarding their relevance for answering the research question at hand. We excluded papers that do not allow conclusions to be drawn about their underlying understanding of DT success, that do not name any success dimensions, or do not offer any indication of possibilities for success measurement. This resulted in the final literature sample of 39 papers (see Table 1). The final sample included no study published prior to 2014, and more than half of the studies (24) were published after 2017. To analyze the literature, we followed an inductive logic in an iterative process, deriving and coding the success dimensions the papers alluded to. From some papers we derived only a single success dimension, while others contained several dimensions. Success dimensions we found in the papers constructed out of multiple distinct sub-dimensions were disaggregated. For instance, we would disaggregate "mature people \& culture" [36] to its elements "structure", "leadership", and "competencies". We derived a total of 115 dimensions across all papers. Next, during three iteration cycles, we aggregated identical or highly similar and related dimensions. For instance, "leadership", "mindset", and "culture" were aggregated to the dimension "culture \& leadership". This procedure resulted in a final 
set of 20 distinct success dimensions. These success dimensions were then clustered according to their underlying notion of DT success, resulting in four clusters. To test the consistency, plausibility, and differentiation of the success dimensions and clusters, we conducted a validation process in two workshops with two researchers, who had not been involved in the coding process, after which we made a few minor alterations.

Table 1. Literature sample

\begin{tabular}{|l|}
\hline Journals (No. of papers in final sample, TOTAL: 15) \\
\hline $\begin{array}{l}\text { European Journal of Information Systems (2), Journal of Strategic Information Systems (2), MIS } \\
\text { Quarterly (2), MIS Quarterly Executive (3), Other Journals (6) }\end{array}$ \\
\hline Conferences (No. of papers in final sample, TOTAL: 24) \\
\hline AMCIS (3), ECIS (5), HICSS (3), ICIS (7), PACIS (2), WI (3), Other Conferences (1) \\
\hline
\end{tabular}

\section{Results}

In the following section we present the resulting DT success dimensions and group them into four clusters. The different clusters reflect different underlying notions (or philosophies) of what DT success is. Importantly, these clusters are not mutually exclusive, nor without overlap. Also, the identified dimensions within the clusters are not independent of each other, nor are they collectively exhaustive.

Cluster I - Overall company value and performance. Cluster I comprises all the success dimensions that directly relate to the entire company's success (see Table 2). The underlying premise here is that DT activities need to contribute directly to such overall success. The first dimension in this cluster, the company value, can already be considered as the most comprehensive success dimension. Potentially, all activities in the company have an effect on this dimension. If it were possible to show that a DT activity has a positive effect on company value, there would probably be no need to assess further success dimensions. However, the actual value of a company is difficult to determine, which is why the identified papers used stock market figures [37], [38]. Efficiency \& profitability is similarly measured primarily by means of stock market figures and accounting figures, such as earnings per share (e.g., [39]), return on assets (ROA) (e.g., [38]), or abnormal stock returns (e.g., [40]). The next dimension, sales volume \& customer base, primarily reflects growth, based on sales revenue (e.g., [41], [42]) and the customer base (e.g., [43], [44]). However, there are also non-financial dimensions in cluster I. Company reputation \& customer satisfaction reflects the public perception of the company and its standing among customers, e.g., by measuring brand key performance indicators (KPIs) [45], [46] or customer satisfaction scores [47]. Workplace quality assesses employees' satisfaction (e.g., [16], [47]) and the resulting turnover rates (e.g., [42]).

In general, success dimensions in cluster I measure the fulfillment of overarching company goals on a macro level. However, it is not always possible to identify how a specific activity contributes to these encompassing macro objectives. This makes the direct use of many of these success dimensions for the operational evaluation of DT activities particularly challenging. Further, some of the dimensions rely heavily on 
stock market figures, which can only be determined for publicly listed companies. In this cluster, most dimensions can be financially calculated and therefore also measured quantitatively; however, there are also qualitative, non-financial and intangible dimensions included. Cluster I contains dimensions that are used as standalone measures (e.g., [37], [40]).

Table 2. Overview cluster I - Overall company value and performance

\begin{tabular}{|l|l|l|}
\hline Success dimension & Exemplary measurement approaches & Sources \\
\hline Company value & Market cap; market-to-book ratio & {$[37],[38]$} \\
\hline Efficiency \& profitability & Earnings per share; operating margin; ROA & {$[38-40],[47-50]$} \\
\hline $\begin{array}{l}\text { Sales volume \& } \\
\text { customer base }\end{array}$ & $\begin{array}{l}\text { Total turnover; market share growth; growth of } \\
\text { customer base }\end{array}$ & $\begin{array}{l}{[26],[41-44],[48],} \\
{[49]}\end{array}$ \\
\hline $\begin{array}{l}\text { Company reputation \& } \\
\text { customer satisfaction }\end{array}$ & $\begin{array}{l}\text { Online brand KPIs; brand index score; customer } \\
\text { satisfaction score }\end{array}$ & {$[42],[45-47]$} \\
\hline Workplace quality & Employee turnover and satisfaction & {$[16],[42],[47]$} \\
\hline
\end{tabular}

Cluster II - Digital business performance. The second cluster follows the premise that successful DT primarily involves creating and exploiting digital business areas, i.e., the profitable marketing of digital products, services, and business models (see Table 3). More abstractly, this is referred to as generating revenue through the deployment of digital technologies [30]. However, sales of physical products via digital channels is also included here [46]. This is reflected very directly in the dimension revenue from digital business, which assesses the growth of digital business. Also, the profitability of digital business is occasionally used as a success criterion. Another dimension in this cluster, reflecting a slightly different notion of DT success, is the relative importance of digital business. Here, scholars consider success to be reflected in digital business growth relative to other business areas, i.e., within the company the digital business share increases. The underlying premise here is that the digital business should become an important pillar of the overall business, possibly even replacing the prevalent core business. Not surprisingly, we also found reference to this success dimension in two papers in the media industry context. They explicitly mentioned that digital business will at least partially replace the traditional business [26], [51].

Cluster II can be closely related to cluster I, since successful digital business has an impact on the overall performance of the company and thus on its value [26], [46]. However, this does not always have to be the case, e.g., if digital business fields cannibalize companies' traditional fields it is conceivable that the effects overall will be neutral or negative. This is particularly evident with the relative importance of digital business, which could also be increased, if the core business shrinks, while digital business revenue remains the same. Accordingly, we distinguish clusters I and II, since cluster I measures whether the entire company is performing better through DT, while cluster II is exclusively oriented toward a company's digital business. Overall, the dimensions in this cluster are quantitative, financial, and tangible, thus relatively precise and continuously measurable. 
Table 3. Overview cluster II - Digital business performance

\begin{tabular}{|l|l|l|}
\hline Success dimension & Exemplary measurement approaches & Sources \\
\hline $\begin{array}{l}\text { Revenue from digital } \\
\text { business }\end{array}$ & $\begin{array}{l}\text { Revenue from digital products and services; sales } \\
\text { from online channels }\end{array}$ & [30], [46], [52-55] \\
\hline $\begin{array}{l}\text { Relative importance of } \\
\text { digital business }\end{array}$ & $\begin{array}{l}\text { Share of new digital business revenue relative to } \\
\text { total revenue; share of revenue from all online } \\
\text { sources }\end{array}$ & [26], [51], [52] \\
\hline $\begin{array}{l}\text { Profitability of digital } \\
\text { business }\end{array}$ & $\begin{array}{l}\text { Digital products' and services' profitability; online } \\
\text { sales profitability }\end{array}$ & [46], [55] \\
\hline
\end{tabular}

Cluster III - Degree of realized external transformation. One condition for generating revenue with digital business is the availability of corresponding digital market offerings. In cluster III, DT success is defined as the realized transformation of market offerings (products and services), customer interaction (channels and touchpoints), partner networks, and overall business models (see Table 4). In contrast to cluster II, the focus here is more on evaluating the progress of the transformation and innovation process itself, not the economic output resulting from the process. Most dimensions in the cluster directly reflect how far an organization's value creation has been transformed, which is argued to be a central specific of DT [2], [34]. A significant number of dimensions in this cluster is derived from maturity models that aim to assess an organizations DT progress along multiple dimensions (e.g., [35], [36], [56]). The two most dominant dimensions in this cluster are digital business model innovation and new digital products \& service innovation. These dimensions are considered as core aspects of transforming the value creation and they reflect a firm's ability to create new digital market offerings. For example, scholars assess whether the company has digital business models (e.g., [34], [39]) and if so, how advanced they are (e.g., [28], [36]), or they determine how many digital products and services (e.g., [51], [57]), digital patents (e.g., [38]), or product innovation projects (e.g., [52]) there are. These two dimensions prompt the distinction of a third dimension: digitalization of existing products \& services, which indicates how far the existing offering is transformed, i.e., it reflects a different aspect of DT (e.g., [29]). However, further dimensions included in cluster III are not directly connected to digital products and services. The externally oriented DT's success can also be determined by assessing the digitalization of customer interaction, e.g., by the number of digital customer channels (e.g., [57]), the maturity of digital customer experience (e.g., [36], [56]), or the partner network area, e.g., by evaluating the cooperative value creation maturity (e.g., [6]).

To summarize, the dimensions in this cluster primarily assess the extent of externally oriented DT activities, but not their economic results. The measures we found can be both, qualitative and quantitative, as well as both tangible and intangible, but they are specifically non-financial. Consequently, taking purely quantitative measurement approaches to capture data (e.g., calculating numbers of products and patents, etc.) appears to be relatively easy. However, to increase their meaningfulness, quantitative measures often are combined with qualifying dimensions (e.g., the quality and responsiveness of development). 
Table 4. Overview cluster III - Degree of realized external transformation

\begin{tabular}{|l|l|l|}
\hline Success dimension & Exemplary measurement approaches & Sources \\
\hline $\begin{array}{l}\text { Digital business model } \\
\text { innovation }\end{array}$ & $\begin{array}{l}\text { Number of realized digital business model } \\
\text { innovations }\end{array}$ & $\begin{array}{l}{[2],[13],[28],[34],} \\
{[36],[39],[58-61]}\end{array}$ \\
\hline $\begin{array}{l}\text { New digital products \& } \\
\text { service innovation }\end{array}$ & $\begin{array}{l}\text { Number of digital products and services; number of } \\
\text { innovation projects; quality, continuity and } \\
\text { responsiveness of digital products development }\end{array}$ & $\begin{array}{l}{[27],[29],[35],[36],} \\
{[38],[41],[48],[51],} \\
{[52],[55-57],[59]}\end{array}$ \\
\hline $\begin{array}{l}\text { Digitalization of existing } \\
\text { products \& services }\end{array}$ & $\begin{array}{l}\text { Existence and number of digitally enriched core } \\
\text { products }\end{array}$ & {$[26],[29],[35]$} \\
\hline $\begin{array}{l}\text { Digitalization of } \\
\text { customer interaction }\end{array}$ & $\begin{array}{l}\text { Number and degree of digital customer channels } \\
\text { utilized; maturity of digital customer touchpoints }\end{array}$ & {$[36],[52],[56],[57]$} \\
\hline Partner network & Maturity of partner network, hybrid value creation & {$[6],[56]$} \\
\hline
\end{tabular}

Cluster IV - Degree of realized internal transformation. All three previously discussed clusters are based on the fact that the organization itself is also changing, although these clusters' dimensions do not directly evaluate the progress of this internal transformation (see Table 5). Thus, cluster IV focuses on realized DT of the organization's structures, processes, and employees. The underlying premise is that successfully realized DT leads to a transformed internal organization. Similar to cluster III, many of the dimensions clustered here are derived from maturity models (e.g., [35], [36], [56]). Also similar to cluster III, literature contributing to this cluster follows multi-dimensional approaches to assess DT success, i.e., researchers measure success along multiple dimensions. The dimension strategy expresses the extent to which a digital strategy, vision, and agenda are present, mature, and continuously being developed (e.g., [35], [56]). It also indicates the extent to which the employees and management understand and accept this strategy (e.g., [52]). The dimension structure, collaboration, \& governance reflects a range of changes to the organizational structure that are often seen as relevant successful DT outcomes, such as organizational agility (e.g., [56]) or self-organized teams (e.g., [36]). The dimension processes assesses the extent to which process innovations have been realized (e.g., [28], [41]) and to which they contribute to quality improvements (e.g., [47]). This is one of the few dimensions in the cluster that is directly quantifiable, e.g., measuring the cost reduction brought on by process improvements (e.g., [53], [55]). Next, the company's IT transformation is regularly assessed to determine the DT progress. This dimension considers the extent to which the IT infrastructure matures and develops further on a technological level (e.g., [6], [56]), but also the extent to which the IT department assumes its role as a DT driver (e.g., [36]). The next two dimensions primarily deal with the aspect of people in DT. Culture \& leadership assesses the presence and maturity of organizational features such as innovative culture, mindset, and leadership style, while competencies \& knowledge targets the maturity of digital skill, competence, and knowledge management. Lastly, partner management corresponds to the dimension partner network in cluster III, but focuses more on the maturity of the internal procedures to facilitate cooperating with partners. 
Overall, many of the dimensions found in this cluster can and also are considered DT enablers or success factors. However, as they are also used to measure the success of DT activities and the progress of the DT process (e.g., [16], [47], [52]), we have included them here. The dimensions in this cluster reflect the most profound aspects of organizational transformation. Regarding measurability, most of the dimensions in this cluster are obviously qualitative, non-financial, and intangible, which largely impedes their direct, objective measurement. Maturity models try to remedy this situation by providing concrete criteria, which can be used to estimate the progress in a dimension (e.g., [35], [36], [56]). However, these models often require a specific understanding or DT focus [62].

Table 5. Overview cluster IV - Degree of realized internal transformation

\begin{tabular}{|l|l|l|}
\hline Success dimension & Exemplary measurement approaches & Sources \\
\hline Strategy & $\begin{array}{l}\text { Maturity, acceptance, and transparency of digital } \\
\text { vision, agenda, and strategy }\end{array}$ & {$[28],[35],[52],[56]$} \\
\hline $\begin{array}{l}\text { Structure, collaboration } \\
\& \text { governance }\end{array}$ & $\begin{array}{l}\text { Maturity of organizational structure, agility, digital } \\
\text { team set-up, teamwork, management support }\end{array}$ & $\begin{array}{l}{[6],[28],[35],[36],} \\
{[56],[58]}\end{array}$ \\
\hline Processes & $\begin{array}{l}\text { Maturity of processes, process effectiveness, process } \\
\text { efficiency, number of process innovations }\end{array}$ & $\begin{array}{l}{[27],[28],[35],[36],} \\
{[41],[47],[53],[55],} \\
{[56], ~[59], ~[63]}\end{array}$ \\
\hline IT & $\begin{array}{l}\text { Maturity of IT infrastructure; reliability, availability, } \\
\text { and performance of IT }\end{array}$ & $\begin{array}{l}{[6],[16],[35],[36],} \\
{[56]}\end{array}$ \\
\hline Culture \& leadership & $\begin{array}{l}\text { Maturity of innovation culture, digital affinity, } \\
\text { digital mindset, leadership }\end{array}$ & $\begin{array}{l}{[6],[35],[36],[52],} \\
{[56]}\end{array}$ \\
\hline $\begin{array}{l}\text { Competencies \& } \\
\text { knowledge }\end{array}$ & $\begin{array}{l}\text { Maturity of digital skills, competencies, knowledge } \\
\text { management }\end{array}$ & $\begin{array}{l}{[6],[35],[36],[47],} \\
{[56]}\end{array}$ \\
\hline Partner management & Maturity of procedures for cooperating with partners & {$[6],[56]$} \\
\hline
\end{tabular}

\section{$5 \quad$ Implications for Research on DT Success}

Looking at the clusters in relation to one another, there is a systemization along two axes (see Figure 1). First, a distinction along two main paradigms becomes visible: achievement of company's core objectives and progress of company's DT process. The former defines DT success in terms of its effect on the overall firm success, i.e., success is determined by DT activities' direct contribution to the ultimate company objectives (e.g., [37], [38]). This paradigm is mainly reflected in clusters I and II, where an outcome-centric, macro-level perspective prevails. The latter defines DT success in terms of progressing the DT process, i.e., success is determined by the extent DT activities contribute to the company's desired state of becoming more digitally transformed (e.g., [29], [36]). This paradigm is mainly reflected in clusters III and IV, where a process-centric, micro-level perspective prevails. Second, a distinction can be made along the orientation of the clusters: internally (transformation of the organization) and externally (transformation of the market offering). Cluster III and IV can be classified quite clearly as externally (III) and internally (IV) oriented. Cluster I 
covers the entire company with its overarching objectives and thus spans both the internal and external perspectives. Cluster II has proven to be primarily externally oriented, since all dimensions relate to the digital business offerings' market success. We find that some articles can be located exclusively in one cluster and thus take a clear position on the notion of DT success (e.g., [37], [40], [43]). Other articles include success dimensions of several different clusters and thus emphasize the multi-faceted nature of DT success (e.g., [35], [36], [52]). Further, some researchers clearly aim to quantify DT outcomes (e.g., [38], [41]), while others strive to refine purely qualitative assessments (e.g., [36], [56]). Based on this comparison and the overall literature analysis, we consider three fields to be particularly important for research in the area of DT success.

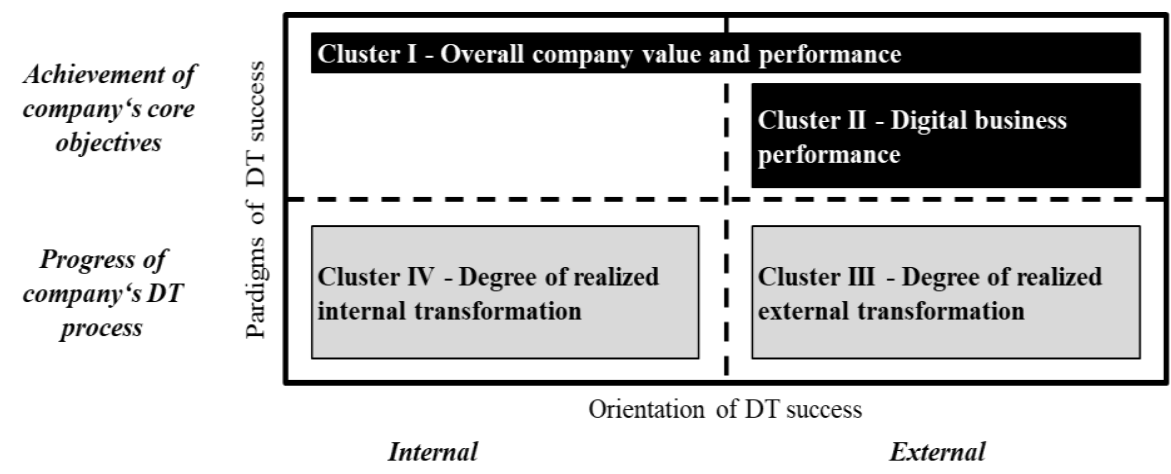

Figure 1. Overview of DT success clusters

Concretization of DT success. We have recognized different paradigms and orientations of DT success, therefore it is important for researchers to be aware of where they are located and on what premises they are built. Of the 121 papers that were shortlisted, i.e., those dealing with DT success generally, we included only 39 in the final analysis because they were, at least to a reasonable degree, specific about the notion of DT success. Given the large variety of possible DT outcomes, the premises underlying DT success can be highly dependent on the vision an organization or industry pursues regarding DT (e.g., relative importance of digital business for the media industry). Thus, different organizations in different contexts measure different dimensions to capture DT success. It is therefore understandable that literature often remains unspecific regarding the DT success notion. Nevertheless, this lack of specificity also risks that the DT success concept remains elusive. This can then lead to the impression that DT success is fundamentally indeterminable and therefore cannot be measured. However, this is not a satisfactory circumstance in IS research and does not meet the requirements existing in reality [9], [10]. Thus, future research should further assist in making DT success concrete and be clear when referring to DT success. For instance, research on DT success factors should include the underlying premise of DT success. In addition, research could examine the latent expectations organizations have of DT to make the implicit notions of success more tangible. 
Investigating DT success notions in real-world contexts. Across all clusters, there are only a few evaluation approaches that are actually applied in an organizational context. The papers we analyzed primarily report on DT success dimensions either still in a conceptual state or ones only used for scientific studies. Several of the measures we came across are not necessarily applicable in practice, as, for example, they require a company to be publicly listed (e.g., [37], [38]). We rarely found any approaches actually utilized in practice to operationally measure DT activities' success that can also support actual managerial decision making. The exceptions were mostly either focused on one specific DT area (e.g., [46]) or on a very top-down, strategic level (e.g., [26], [30]). Ryan et al. present a holistic approach, covering multiple dimensions as they were measured in the real-world context; however, the approach is also very specific to a health management setting [47]. Seeher et al. identify a range of metrics that are applied in practice; however, not linked to one specific case, as they were based on a Delphi study [52]. Besides what these articles report, there currently appears to be a knowledge gap on how companies in practice measure their DT activities' success. Thus, we highly recommend future research to find relevant cases, to identify and investigate DT success measurement approaches in their real-world context.

Development of holistic but concise success measurement approaches. The different paradigms and orientations all reflect relevant DT outcomes and also show how DT success can be measured. There are however reasons to assume that companies are still struggling to find appropriate approaches for measuring their DT success [9]. Accordingly, future research could take up this challenge and contribute to developing new measurement approaches. The dimensions and clusters identified in this study could provide a basis for this. Since the dimensions are often interdependent, it could also be useful to consider them in combination. We propose aligning the dimensions in a way that combines strengths and mitigates weaknesses. For example, an attempt could be made to link the dimensions of clusters III and IV directly to clusters I and II in order to identify how implementation DT activities affects the overall objectives. It is also important to clarify the question of where to measure. We have found different approaches here, e.g., those at the level of the chief digital officer (e.g., [52]), in individual projects or project portfolios (e.g., [55]), in the digital business division (e.g., [54]), or at the level of the overall organization (e.g., [37]). We argue that it is important to be able to evaluate the overall success of the organizational DT. However, for the operational management of DT, it is also important to evaluate individual activities regarding their contribution to the overall DT success [9].

\section{Conclusion, Limitations and Outlook}

This study investigated the notion of DT success and related success measurement approaches in current IS literature. Therefore, we conducted a systematic literature search that yielded 39 papers. Analyzing these papers, we derived 20 individual success dimensions and assigned them to four clusters. The identified dimensions were analyzed within and between the clusters in order to learn how DT success is conceptualized in IS literature and to find out which measurement approaches are 
applied in practice and research. Finally, to support further attempts to improve our understanding of DT success, we have presented three recommendations for future research in this area.

With these results, we enrich the existing IS success literature by providing a first comprehensive overview of DT success, thus extending this established IS research strand from a primarily technology-centric perspective, to the more holistic perspective of digital innovation and transformation. We show that many topics already dealt with in the IS success literature (e.g., "hard" vs. "soft" criteria, "macro" vs. "micro" level measuring) are also relevant for DT success. However, with a few exceptions (e.g., [10], [16]), DT success measures have, to date, hardly been critically discussed. Further, we contribute to DT literature by discussing and systematizing various concurrent notions of DT success. By uncovering different DT success perspectives and paradigms, we hope to foster understanding of what DT success entails and to link the assumptions of what constitutes such success to specific success dimensions. Further, we demonstrate, how DT success can be measured on different levels, be it in the overall organization (macro) or regarding single transformation activities (micro). By discussing different approaches, we hope to support future research that will clarify the notion of DT success, identify and investigate applied measurement approaches in their real-world context, or even contribute to developing new measurement approaches. Overall, our study aims to reduce the elusiveness of DT success, as we consider this an important factor in maintaining and increasing the legitimacy of research in the DT field.

This study intends to motivate practitioners to deal extensively with the matter of DT success and consequently to assess their own DT activities. For this, they receive indications on which success dimensions and specific measurement approaches can be suitable for which type of DT objective. This study is subject to a set of limitations. The results depend partly on the underlying understanding of DT. Researchers with different assumptions might come up with different results. We therefore strived to make our assumptions and premises, as well as our overall review process, transparent. Further, this study's results do not provide a complete framework of all the success dimensions relevant in reality; they only reflect what we found in the analyzed literature. It is likely that there are other relevant dimensions. Thus, we want to encourage researchers to take up on these suggestions regarding areas of possible improvement, to further clarify the DT success concept and to investigate and advance measurement approaches applied in practice.

\section{References}

1. Hanelt, A., Bohnsack, R., Marz, D., Antunes Marante, C.: A Systematic Review of the Literature on Digital Transformation: Insights and Implications for Strategy and Organizational Change. Journal of Management Studies 1-39 (2020)

2. Wessel, L., Baiyere, A., Ologeanu-Taddei, R., Cha, J., Jensen, T.: Unpacking the Difference Between Digital Transformation and IT-Enabled Organizational Transformation. Journal of the AIS, forthcoming, 1-57 (2020) 
3. Wiesböck, F., Hess, T.: Digital Innovations - Embedding in Organizations. Electronic Markets 30, 75-86 (2020)

4. Berghaus, S., Back, A.: Disentangling the Fuzzy Front End of Digital Transformation: Activities and Approaches. In: Proceedings of the 38th International Conference on Information Systems (ICIS), pp. 1-17. (2017)

5. Vial, G.: Understanding Digital Transformation: A Review and a Research Agenda. The Journal of Strategic Information Systems 28, 118-144 (2019)

6. Vogelsang, K., Liere-Netheler, K., Packmohr, S., Hoppe, U.: Success Factors for Fostering a Digital Transformation in Manufacturing Companies. Journal of Enterprise Transformation $1-22(2019)$

7. Osmundsen, K., Iden, J., Bygstad, B.: Digital Transformation: Drivers, Success Factors, and Implications. In: Proceedings of the 12th Mediterranean Conference on Information Systems (MCIS), pp. 1-15. (2018)

8. Morakanyane, R., O'Reilly, P., McAvoy, J., Grace, A.: Determining Digital Transformation Success Factors. In: Proceedings of the 53rd Hawaii International Conference on System Sciences (HICSS), pp. 4356-4365. (2020)

9. Gimpel, H., Hosseini, S., Huber, R., Probst, L., Röglinger, M., Faisst, U.: Structuring Digital Transformation: A Framework of Action Fields and its Application at ZEISS. Journal of Information Technology Theory and Application 19, 31-54 (2018)

10. Neumeier, A., Wolf, T., Oesterle, S.: The Manifold Fruits of Digitalization - Determining the Literal Value Behind. In: Proceedings of the 13th Internationale Tagung Wirtschaftsinformatik (WI), pp. 484-498. (2017)

11. DeLone, W.H., McLean, E.R.: The DeLone and McLean Model of Information Systems Success: A Ten-Year Update. Journal of Management Information Systems 19, 9-30 (2003)

12. Schryen, G.: Revisiting IS Business Value Research: What We Already Know, What We Still Need to Know, and How We Can Get There. European Journal of Information Systems 22, 139-169 (2013)

13. Holotiuk, F., Beimborn, D.: Critical Success Factors of Digital Business Strategy. In: Proceedings of the 13th Internationale Tagung Wirtschaftsinformatik (WI), pp. 991-1005. (2017)

14. Böttcher, T.P., Weking, J.: Identifying Antecedents and Outcomes of Digital Business Model Innovation. In: Proceedings of the 28th European Conference on Information Systems (ECIS), pp. 1-14. (2020)

15. Bordeleau, F.-È., Felden, C.: Digitally Transforming Organisations: A Review of Change Models of Industry 4.0. In: Proceedings of the 27th European Conference on Information Systems (ECIS), pp. 1-14. (2019)

16. Liere-Netheler, K., Vogelsang, K., Packmohr, S., Hoppe, U.A.: Towards a Framework for Digital Transformation Success in Manufacturing. In: Proceedings of the 26th European Conference on Information Systems (ECIS), pp. 1-19. (2018)

17. Kohli, R., Grover, V.: Business Value of IT: An Essay on Expanding Research Directions to Keep up With the Times. Journal of the AIS 9, 23-39 (2008)

18. Gable, G.G., Sedera, D., Chan, T.: Re-Conceptualizing Information System Success: The ISImpact Measurement Model. Journal of the AIS 9, 377-408 (2008)

19. Irani, Z., Love, P.E.: Developing a Frame of Reference for Ex-Ante IT/IS Investment Evaluation. European Journal of Information Systems 11, 74-82 (2002) 
20. Melville, N., Kraemer, K., Gurbaxani, V.: Information Technology and Organizational Performance: An Integrative Model of IT Business Value. MIS Quarterly 28, 283-322 (2004)

21. Mandrella, M., Trang, S., Kolbe, L.M.: Synthesizing and Integrating Research on IT-Based Value Cocreation: A Meta-Analysis. Journal of the AIS 21, 388-427 (2020)

22. Farbey, B., Land, F., Targett, D.: Moving IS Evaluation Forward: Learning Themes and Research Issues. The Journal of Strategic Information Systems 8, 189-207 (1999)

23. Hinings, B., Gegenhuber, T., Greenwood, R.: Digital Innovation and Transformation: An Institutional Perspective. Information and Organization 28, 52-61 (2018)

24. Kohli, R., Melville, N.P.: Digital Innovation: A Review and Synthesis. Information Systems Journal 29, 200-223 (2019)

25. Frey, J., Holotiuk, F., Beimborn, D.: Debating Digital Innovation: A Literature Review on Realizing Value from Digital Innovation. In: Procceedings of the 15th Internationale Tagung Wirtschaftsinformatik (WI), pp. 1-16. (2020)

26. Hess, T., Matt, C., Benlian, A., Wiesböck, F.: Options for Formulating a Digital Transformation Strategy. MIS Quarterly Executive 15, 125-139 (2016)

27. Barthel, P., Fuchs, C., Birner, B., Hess, T.: Embedding Digital Innovations in Organizations: A Typology for Digital Innovation Units. In: Procceedings of the 15th Internationale Tagung Wirtschaftsinformatik (WI), pp. 1-15. (2020)

28. Arvidsson, V., Mønsted, T.: Generating Innovation Potential: How Digital Entrepreneurs Conceal, Sequence, Anchor, and Propagate New Technology. The Journal of Strategic Information Systems 27, 369-383 (2018)

29. Chanias, S., Myers, M.D., Hess, T.: Digital Transformation Strategy Making in Pre-Digital Organizations: The Case of a Financial Services Provider. The Journal of Strategic Information Systems 28, 17-33 (2019)

30. Tumbas, S., Berente, N., vom Brocke, J.: Digital Innovation and Institutional Entrepreneurship: Chief Digital Officer Perspectives of Their Emerging Role. Journal of Information Technology 33, 188-202 (2018)

31. Rowe, F.: What Literature Review Is Not: Diversity, Boundaries and Recommendations. European Journal of Information Systems 23, 241-255 (2014)

32. Paré, G., Trudel, M., Jaana, M., Kitsiou, S.: Synthesizing Information Systems Knowledge: A Typology of Literature Reviews. Information \& Management 52, 183-199 (2015)

33. Webster, J., Watson, R.T.: Analyzing the Past to Prepare for the Future: Writing a Literature Review. MIS Quarterly 26, xiii-xxiii (2002)

34. Gierlich, M., Schüritz, R., Volkwein, M., Hess, T.: SMEs' Approaches for Digitalization in Platform Ecosystems. In: Proceedings of the 23rd Pacific Asia Conference on Information Systems (PACIS), pp. 1-14. (2019)

35. Klötzer, C., Pflaum, A.: Toward the Development of a Maturity Model for Digitalization Within the Manufacturing Industry's Supply Chain. In: Proceedings of the 50th Hawaii International Conference on System Sciences (HICSS), pp. 4210-4219. (2017)

36. Berger, S., Bitzer, M., Häckel, B., Voit, C.: Approaching Digital TransformationDevelopment of a Multi-Dimensional Maturity Model. In: Proceedings of the 28th European Conference on Information Systems (ECIS), pp. 1-18. (2020)

37. Moker, A., Brosi, P., Welpe, I.: It Depends on the Size: How Firm Strategic Emphasis on Digital Transformation Predicts Market Capitalization. In: Proceedings of the 53rd Hawaii International Conference on System Sciences (HICSS), pp. 5472-5481. (2020) 
38. Hanelt, A., Firk, S., Hildebrandt, B., Kolbe, L.M.: Digital M\&A, Digital Innovation, and Firm Performance: An Empirical Investigation. European Journal of Information Systems, forthcoming, 1-24 (2020)

39. Hildebrandt, B., Hanelt, A., Firk, S., Kolbe, L.: Entering the Digital Era - The Impact of Digital Technology-Related M\&As on Business Model Innovations of Automobile OEMs. In: Proceedings of the 36th International Conference on Information Systems (ICIS), pp. 121. (2015)

40. Drechsler, K., Wagner, H.-T., Reibenspiess, V.A.: Risk and Return of Chief Digital Officers' Appointment - An Event Study. In: Proceedings of the 40th International Conference on Information Systems (ICIS), pp. 1-17. (2019)

41. Ferreira, J.J., Fernandes, C.I., Ferreira, F.A.: To Be or Not to Be Digital, That Is the Question: Firm Innovation and Performance. Journal of Business Research 101, 583-590 (2019)

42. Khin, S., Ho, T.C.: Digital Technology, Digital Capability and Organizational Performance. International Journal of Innovation Science 11, 177-195 (2019)

43. Huang, J., Henfridsson, O., Liu, M.J., Newell, S.: Growing on Steroids: Rapidly Scaling the User Base of Digital Ventures Through Digital Innovation. MIS Quarterly 41, 301-314 (2017)

44. Leischnig, A., Wölfl, S., Ivens, B., Hein, D.: From Digital Business Strategy to Market Performance: Insights Into Key Concepts and Processes. In: Proceedings of the 38th International Conference on Information Systems (ICIS), pp. 1-16. (2017)

45. Beutel, S., Bendig, D., Brettel, M.: The Intangible Value of Digitalization - Assessing the Relationship of Digital Orientation and Intangible Value Drivers. In: Proceedings of the 40th International Conference on Information Systems (ICIS), pp. 1-17. (2019)

46. Hansen, R., Sia, S.K.: Hummel's Digital Transformation Toward Omnichannel Retailing: Key Lessons Learned. MIS Quarterly Executive 14, 51-66 (2015)

47. Ryan, J., Doster, B., Daily, S., Lewis, C.: Targeting Perioperative Performance Aligned to Hospital Strategy via DT. In: Proceedings of the 53rd Hawaii International Conference on System Sciences (HICSS), pp. 3628-3637. (2020)

48. Nwankpa, J.K., Roumani, Y.: IT Capability and Digital Transformation: A Firm Performance Perspective. In: Proceedings of the 37th International Conference on Information Systems (ICIS), pp. 1-16. (2016)

49. Nwankpa, J.K., Datta, P.: Balancing Exploration and Exploitation of IT Resources: The Influence of Digital Business Intensity on Perceived Organizational Performance. European Journal of Information Systems 26, 469-488 (2017)

50. Murawski, M., Bühler, J., Martensen, M., Rademacher, C., Bick, M.: How Digital Business Strategy Affects Profitability: Opening the 'Black Box' of Performance. In: Proceedings of the 24th Americas Conference on Information Systems (AMCIS), pp. 1-10. (2018)

51. Karimi, J., Walter, Z.: The Role of Dynamic Capabilities in Responding to Digital Disruption: A Factor-Based Study of the Newspaper Industry. Journal of Management Information Systems 32, 39-81 (2015)

52. Seeher, V., Beimborn, D., Holotiuk, F.: How to Evaluate the Performance of the CDO - A Delphi Study on KPIs for CDOs. In: Proceedings of the 28th European Conference on Information Systems (ECIS), pp. 1-15. (2020)

53. Fichman, R.G., Dos Santos, B., Zheng, Z.: Digital Innovation as a Fundamental and Powerful Concept in the Information Systems Curriculum. MIS Quarterly 38, 329-353 (2014) 
54. Freitas Junior, J.C.d.S., Maçada, A.C.G., Brinkhues, R.A.: Digital Capabilities as Key to Digital Business Performance. In: Proceedings of the 23rd Americas Conference on Information Systems (AMCIS), pp. 1-10. (2017)

55. Wiesböck, F.: Innovating in a Digital World - The Role of Digital Product Innovation Capabilities. In: Proceedings of the 27th European Conference on Information Systems (ECIS), pp. 1-16. (2019)

56. Berghaus, S., Back, A.: Stages in Digital Business Transformation: Results of an Empirical Maturity Study. In: Proceedings of the 10th Mediterranean Conference on Information Systems (MCIS), pp. 1-17. (2016)

57. Leonhardt, D., Hanelt, A., Huang, P., Mithas, S.: Does One Size Fit All? Theorizing Governance Configurations for Digital Innovation. In: Proceedings of the 39th International Conference on Information Systems (ICIS), pp. 1-17. (2018)

58. Muehlburger, M., Rueckel, D., Koch, S.: A Framework of Factors Enabling Digital Transformation. In: Proceedings of the 25th Americas Conference on Information Systems (AMCIS), pp. 1-10. (2019)

59. Sebastian, I., Ross, J., Beath, C., Mocker, M., Moloney, K., Fonstad, N.: How Big Old Companies Navigate Digital Transformation. MIS Quarterly Executive 16, 197-213 (2017)

60. Jöhnk, J., Oesterle, S., Ollig, P., Riedel, L.-N.: The Complexity of Digital Transformation Conceptualizing Multiple Concurrent Initiatives. In: Proceedings of the 15th Internationale Tagung Wirtschaftsinformatik (WI), pp. 1-15. (2020)

61. Soto Setzke, D., Opderbeck, L., Böhm, M., Krcmar, H.: Pathways to Successful Business Model Innovation in the Context of Digital Transformation. In: Proceedings of the 24th Pacific Asia Conference on Information Systems (PACIS), pp. 1-14. (2020)

62. Remane, G., Hanelt, A., Wiesboeck, F., Kolbe, L.: Digital Maturity in Traditional Industries - An Exploratory Analysis. In: Proceedings of the 25th European Conference on Information Systems (ECIS), pp. 143-157. (2017)

63. Soh, C., Yeow, A., Goh, Q., Hansen, R.: Digital Transformation: Of Paradoxical Tensions and Managerial Responses. In: Proceedings of the 40th International Conference on Information Systems (ICIS), pp. 1-17. (2019) 